\title{
Remote Sensing of Large River Basins
}

Soner Uereyen ${ }^{1 *}$, Felix Bachofer ${ }^{1}$, Juliane Huth ${ }^{1}$, Igor Klein ${ }^{1}$, and Claudia Kuenzer ${ }^{1,2}$

${ }^{1}$ German Aerospace Center (DLR), German Remote Sensing Data Center (DFD), Oberpfaffenhofen, Germany 2University Wuerzburg, Institute of Geography and Geology, Wuerzburg, Germany

*E-Mail: soner.uereyen@dlr.de

Researchgate: Publication; Profile 


\section{Background \& Motivation}

- River basins: functional unit of the Earth's land surface $\rightarrow$ they provide an abundance of resources for the environment and humans

- They are highly impacted i.e.: by human-induced changes, boundary conflicts, or upstreamdownstream inequalities

- However, these impacts on land surface and surface water properties of many major river basins remain largely unmonitored at basin scale

- Earth observation (EO) is a potential source of spatial information $\rightarrow$ largescale and temporally dense data allow consistent analyses of river basins

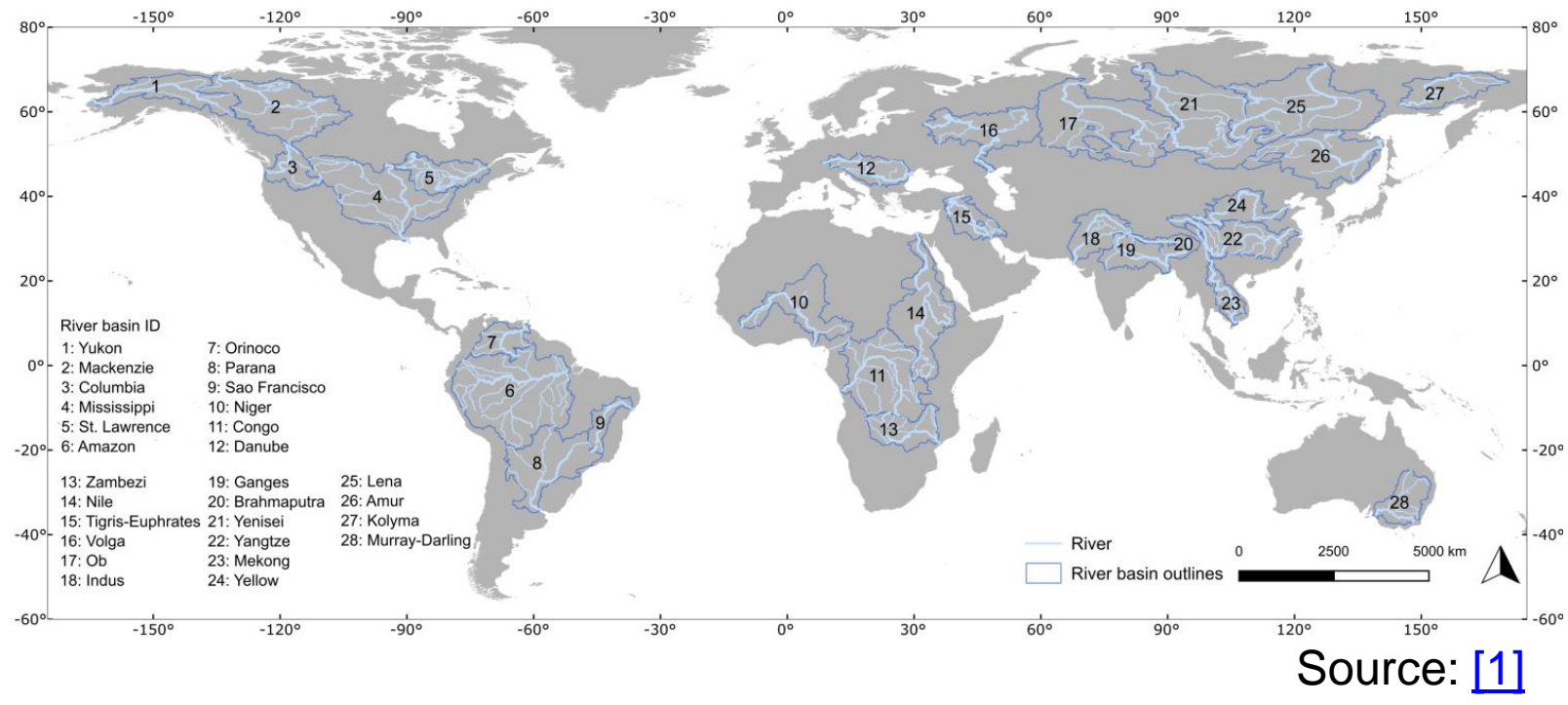

[1] Uereyen, S.; Kuenzer, C. A Review of Earth Observation-Based Analyses for Major River Basins. Remote Sens. 2019, 11, 2951. 


\section{Objectives \& Literature selection}

- We analyzed all available studies focusing on spaceborne characterization of the 28 largest river basins, mainly related to land surface and surface water parameters

- In particular, we summarize:

- Frequently studied parameters categorized in biosphere, hydrosphere, and cryosphere

- Spatial and temporal availability of studies

- Applied remote sensing data sources

- Limitations and potentials of EO for large river basins analyses

- Literature selection criteria:

- Studies use spaceborne remote sensing data to characterize land surface parameters

- Studies investigating on the spatial entity „basin“, „subbasin“, or „regional“ 


\section{EO-based characterization of river basins}

3.1 Spatial distribution of reviewed studies
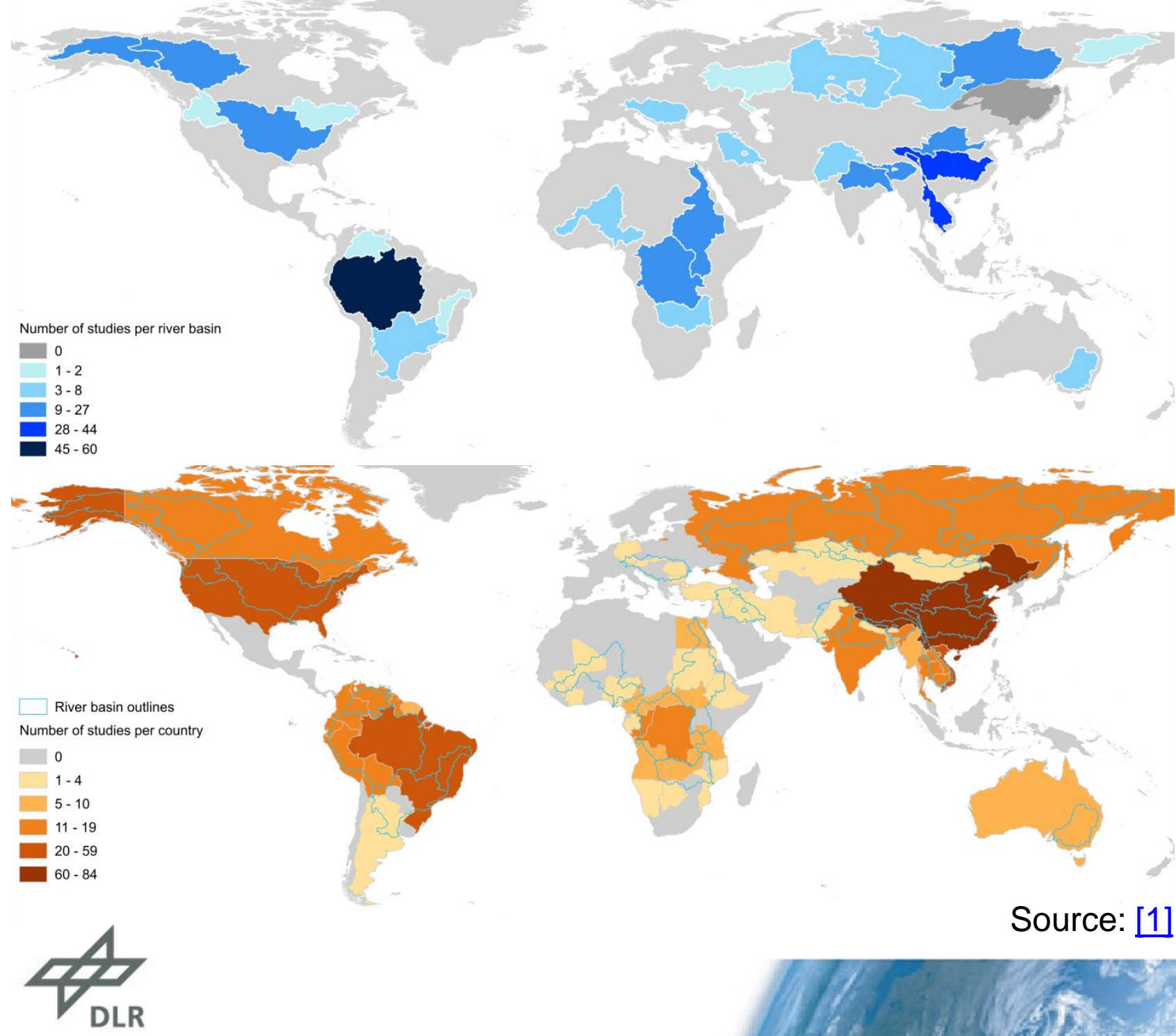

- Most of the studies focused on the Amazon, Yangtze, Mekong, and Yellow river basin

- Even though river basins are functional units, we found that studies often focus on spatial units within national boundaries

- China, Brazil, Vietnam, and the USA were studied most 


\section{EO-based characterization of river basins}

\subsection{Categorization of research foci}

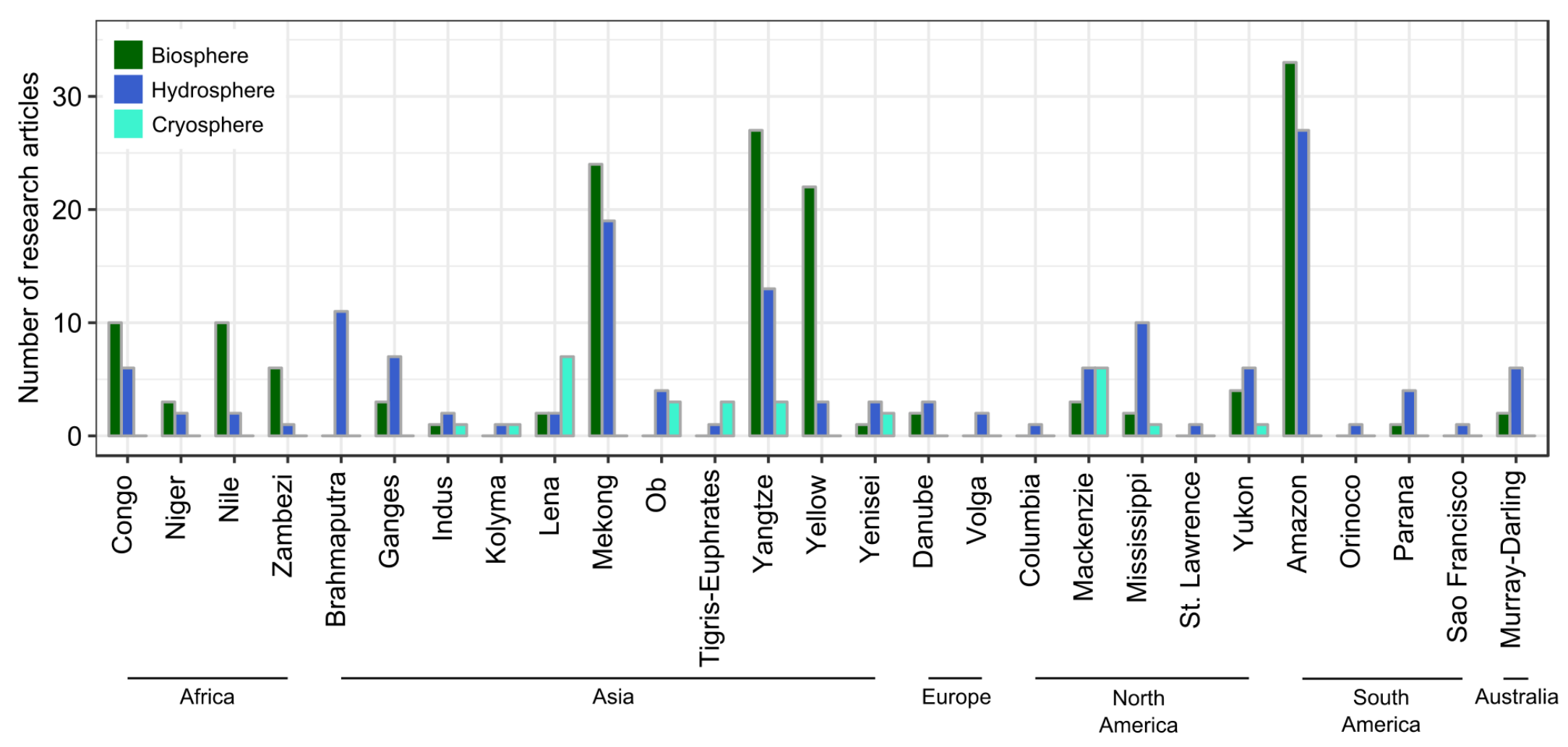

Source: [1]
- Most frequently studied parameters were:

- Biosphere (vegetation, land cover / land use, urban areas, agriculture, coastline)

- Hydrosphere (surface water, water quality, river water level, river discharge)

- Cryosphere (snow and ice cover, permafrost, river and lake ice) 


\section{EO-based characterization of river basins}

\subsection{Temporal resolution of studies}
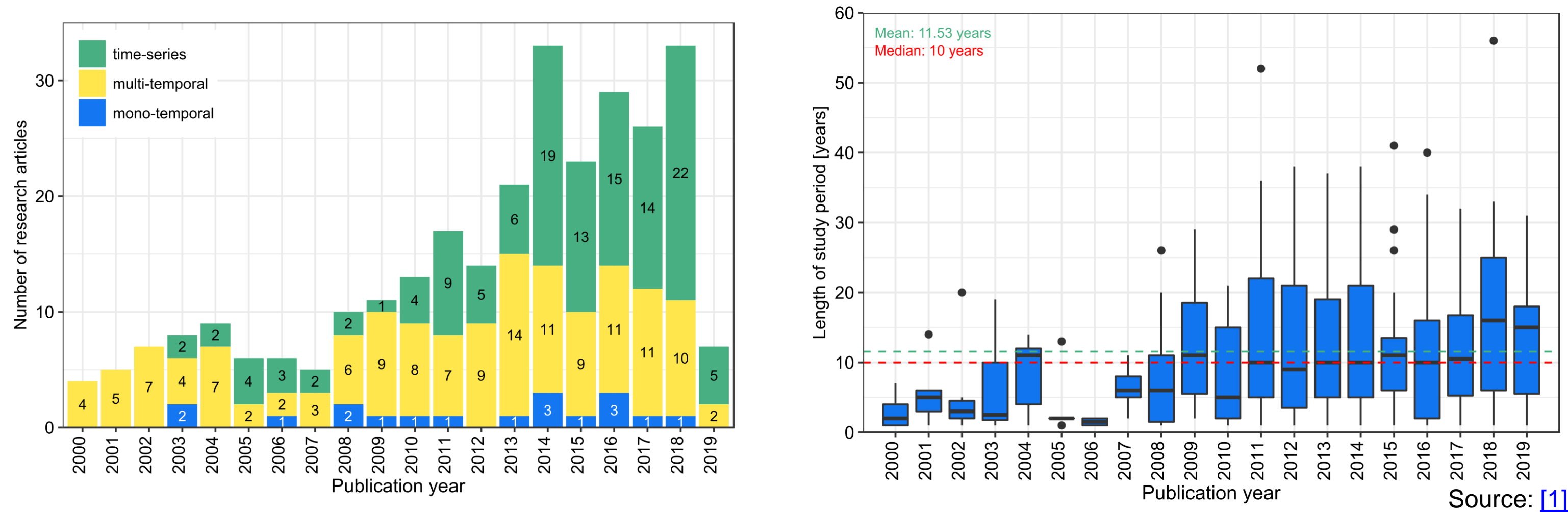

- Studies conducting time-series analysis increased, so did the investigated length of the study period 


\section{EO-based characterization of river basins}

\subsection{Spatial scale of studies}

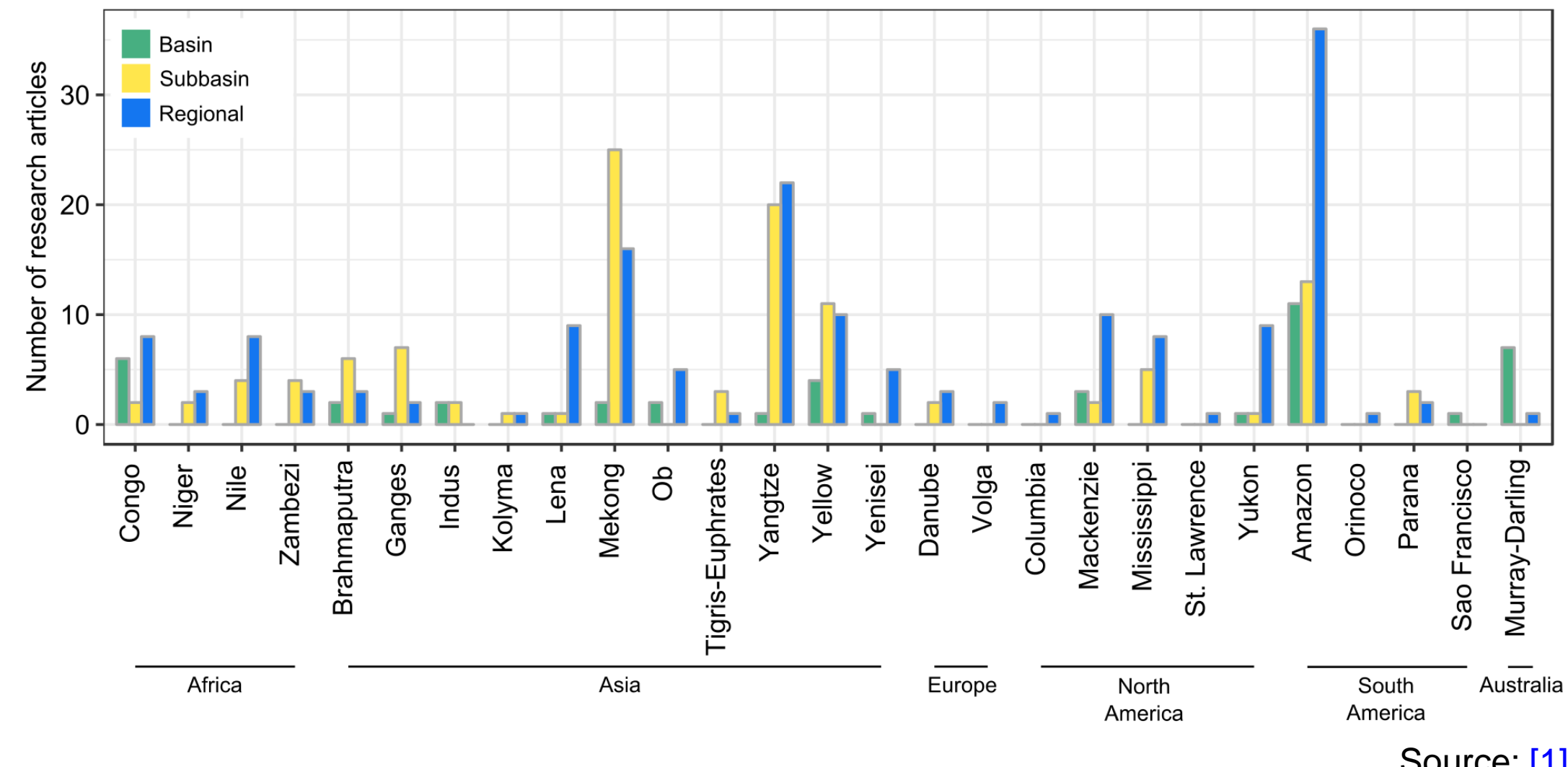

- Frequency of basin wide studies is comparably low, most of them were conducted for the Amazon and MurrayDarling river basin

- Studies at subbasin scale investigated mostly the Mekong, Yangtze, and Yellow river basin

Source: [1] 


\section{Limitations \& Potential of EO}

- Study areas mostly limited to regional or subbasin scale $\rightarrow$ defined i.e. by national boundaries, hence transboundary river basins remain understudied

- During the last years, many EO-based global products (e.g. geophysical or thematic variables) became available $\rightarrow$ such data is essential e.g. for hydrological, climate, and environmental change modeling

- In case of river basin analyses, databases gathering relevant geospatial data are lacking or are not up to date $\rightarrow$ here, increasing amount of free and open geospatial time series data as well as improving processing and technological capacities support consistent EO-based applications for large scale river basin analyses 


\section{Conclusions \& Outlook}

- In this study, we reviewed 287 research articles, most of them focused on research foci related to the biosphere

- Only $14 \%$ of the studies performed basin wide investigations, meaning that EO-based analyses are mostly conducted at subbasin or regional scale

- Synergetic exploitation of available geospatial datasets is important to improve environmental change analysis e.g. with respect to large river basins

- For this purpose, we analyse geospatial time series data including geophysical parameters (e.g. evapotranspiration, net primary productivity, snow water equivalent, soil moisture), thematic variables (e.g. surface water extent, urban extent, snow cover), index variables (e.g. NDVI), as well as climate reanalysis data 